\title{
Cardiovascular Manifestations in Patients Infected with the Human Immunodeficiency Virus
}

Ludhmila Abrahão Hajjar, Daniela Calderaro, Pai Ching Yu, Isabela Giuliano, Enéas Martins de Oliveira Lima, Giuseppe Barbaro, Bruno Caramelli Instituto do Coração do Hospital das Clínicas - FMUSP e Department of Medical Pathophysiology, University La Sapienza, Itália - São Paulo, SP - Brazil and Roma, Itália

Today, it is estimated that the infection caused by the human immunodeficiency virus affects 42 million people worldwide. In Brazil 1,200,000 individuals are infected, and 257,780 of them have the Acquired Immunodeficiency Syndrome (AIDS). AIDS currently accounts for $1.41 \%$ of reported deaths in Brazil, a number that is decreasing owing to the national antiretroviral treatment distribution policy, which provides HIV-infected individuals universal access to available therapy.

The year 1996 is a landmark in the history of HIV infection and separates it into two eras: pre- and post$1996^{1}$. Before 1996 but after detection of the infection in 1981, early diagnosis and treatment of opportunistic diseases were sought. After 1996, with the advent of combined antiretroviral therapy (HAART - Highly Active Antiretroviral Therapy), significant improvements in fighting the infection were achieved, with an increase in survival and an improvement in the quality of life of infected individuals ${ }^{2}$.

The use of combined antiretroviral therapy to increase patients' life span, together with a reduction in opportunistic infections, resulted in the emergence of chronic diseases and conditions related to common risk factors in the general population in this group, especially cardiovascular changes associated with the infection caused by the human immunodeficiency virus and those related to adverse heart effects of antiretroviral agents, which became more significant in recent years ${ }^{3,4}$.

Heart involvement due to the HIV infection was first described in 1983 by Autran et $\mathrm{al}^{5}$ who described a myocardial case of Kaposi's sarcoma in a patient with AIDS. Since then, during the pre-HAART era, prevalences ranging from $28 \%$ to $73 \%$ of heart involvement affecting the pericardium, endocardium, myocardium and vessels were observed in HIV-infected patients-mainly in autopsies $^{6,7}$. There are several cardiovascular manifestations due to the HIV infection itself, autoimmunity, immunological reaction to other viral infections, chronic inflammation, neoplasias, delayed immunosupression, malnutrition and drug cardiotoxicity ${ }^{8,9}$.

Multiple therapy has introduced qualitative changes in cardiovascular manifestations. There has been a decrease in heart conditions caused by opportunistic agents, malnutrition and long-term immunosupression ${ }^{10}$. However, there has been an increase in the number of cases of coronary syndromes and peripheral vascular events related both to the increased survival of HIVinfected individuals and to drug toxicity ${ }^{11,12}$.

Our objective is to discuss the various cardiac manifestations in HIV-infected patients, with a comprehensive literature review emphasizing practical topics related to clinical assessment and our experience treating patients at the Casa da Aids, at the Instituto do Coração, in São Paulo.

\section{Pericardial Diseases}

Pericardial effusion was the most common heart manifestation in the pre-HAART era ${ }^{13}$, with prevalence ranging from $21 \%$ to $30 \%$ in HIV-positive patients and an annual incidence of $11 \%{ }^{14}$. These data indicate that the investigation of pericardial effusion today should include serum HIV detection exams because current studies have detected positive serum when assessing pericardial effusion in $72 \%$ of cases in Africa, 33\% of cases in Europe and in $7 \%$ to $28 \%$ of cases in the USA ${ }^{13,14}$. The presence of pericardial effusion in HIV infection is a marker of the advanced stage of the disease and implies a poorer prognosis, regardless of CD4 cell counts and serum albumin level. Pericardial effusion is associated with shortening survival to an average of six months ${ }^{13,14}$.

Mailing Address: Bruno Caramelli • Rua Cravinhos, 92/101-01408-020-São Paulo, SP - Brazil 
There are many causes of pericardial effusion. In most investigational studies the etiological agent is not found. Cases in which an agent was identified show that the most frequent causes are infections caused by microbacteria followed by bacterium infection and neoplasias. Effusions caused by opportunistic virus (HIV, herpes simplex, adenovirus, coxsackie, cytomegalovirus, Epstein Barr) related to systemic diseases (heart failure, cirrhosis, acute myocardium infarction, uremia, myocarditis) and associated with a chronic inflammatory condition (increased permeability) and malnutrition have been also described ${ }^{15-17}$. Chart I shows the causes of pericardial effusion in HIV-infected patients.

The clinical picture of pericardium involvement is extensive, ranging from total absence of symptoms to the occurrence of shock and cardiopulmonary arrest. Fever,

Chart I - Causes of pericardial effusion in HIV-positive patients. EBV: Epstein Barr virus, HSV: herpes simplex virus; CMV: cytomegalovirus; CHF: congestive heart failure; AMl: acute myocardial infarction

$\begin{array}{ll}\text { Mycobacterium tuberculosis } & \text { Chlamydia trachomatis } \\ \text { Mycobacterium avium intracellulare } & \text { Coxsackie/EBV/HSV } \\ \text { Staphylococcus aureus } & \text { Adenovirus/CMV/HIV } \\ \text { Nocardia asteroides } & \text { Histoplasma/Cryptococcus } \\ \text { Rhodococcus equi } & \text { Kaposi's sarcoma/Lymphoma } \\ \text { Endocardite } & \text { Toxoplasma gondii } \\ \text { Listeria monocytogenes } & \text { CHF/AMI/Cirrhosis/Uremia/Myocarditis } \\ \text { Inflammation } & \text { Malnutrition }\end{array}$

chest pain and coughing may be present. Pericardial involvement includes pericarditis, effusion with or without tamponade, constrictive pericarditis and neoplasic infiltration ${ }^{13,18}$. Most effusions are mild, without any hemodynamic change, with an annual incidence of $9 \%$ of tamponade. Chen et $\mathrm{al}^{15}$ examined 122 cases of pericardial effusion and 40 were HIV-positive patients. Of these forty patients, effusion was mild in $45 \%$ and moderate in $25 \%$. The cause was not found in the other $63 \%$ of cases and mycobacteriosis affected $19 \%$ of them. Gowda et al ${ }^{19}$ described 185 cases of cardiac tamponade in AIDS patients. The etiological study showed the presence of mycobacteriosis in $43 \%$, bacteria in $11 \%$, Iymphoma in $8 \%$ and Kaposi's sarcoma in $7 \%$. The agent was not identified in $26 \%$ of the cases.

Studies assessing pericardial effusion in HIV-infected patients do not show any relationship between the infection status and the severity of the effusion ${ }^{19,20}$. In $42 \%$ of the cases, pericardial effusion is self-limited, with spontaneous resolution, which does not exclude poor prognosis associated with its detection ${ }^{19,20}$. In the study conducted by Gowda et al, most patients died during hospitalization or soon after, indicating that pericardial effusion is a marker of the advanced stage of the disease ${ }^{19}$.

Echocardiography confirms the clinical suspicion of pericardial effusion. M-mode echocardiography can help reveal the characteristics of cardiac tamponade: compression of the right atrium and right ventricular diastolic collapse. These signs precede the pulsus paradoxus and the respiratory insufficiency secondary to cardiac tamponade.

There is debate regarding the best approach to managing pericardial involvement, particularly regarding if the search for etiological diagnosis is valid. Different rates of etiological identification are seen in the literature in accordance with the techniques used - direct analysis, cytology, immunofluorescence, immunoenzimatic tests, polymerase chain reaction, cultures or biopsies ${ }^{13,15,18,20,21}$. To this end, periocardiocentesis or pericardiostomy can be performed via biopsy. Both techniques involve higher risk for HIV-positive patients and have been carried out, in general, only in patients with severe, poorly-tolerated effusions with tamponade that do not show any improvement or as an attempt to diagnose a systemic disease. The method of choice varies according to individual experience, although pericardiostomy with biopsy seems to be the most appropriate.

Little is known about the effects of HAART in HIVrelated pericardial conditions. The number of pericardial effusion cases is expected to decline during at the postHAART era since it is associated with the advanced stage of HIV infection and immunosuppresion. Eradication or control of the viral infection results in a smaller number of opportunistic diseases and neoplasias, reducing the number of cases of pericardial disease.

\section{Diseases of the Endocardium}

The frequency of endocarditis in patients with HIV infection is similar to the frequency observed in patients of other risk groups, such as intravenous drug users ${ }^{22}$. HIV infection does not increase the frequency nor the severity of endocarditis. The incidence of endocarditis in HIV-infected patients and toxic intravenous drug users ranges from $6 \%$ to $34 \%$ and their survival rate is similar to that of HIV-negative patients with endocarditis $(85 \% \mathrm{x}$ $93 \%)^{22,23}$. Mortality rate caused by endocarditis is $30 \%$ higher in patients in the advanced stage of the infection ${ }^{24}$.

Endocarditis in toxic intravenous drug users usually affects the valves on the right side - the tricuspid in 90\% and the pulmonary in $10 \%$ of cases ${ }^{24}$. Twenty percent of the patients have simultaneous commitment of the mitral or aortic valve, which results in a poor prognosis. The clinical picture varies: fever, poor general condition, weight loss, sudoresis, clinical manifestations of pulmonary or systemic embolization, and in some cases, association with meningitis and pneumonia. Due to a higher rate of tricuspid valve endocarditis, pulmonary embolizations with subsequent infarctions are frequent, present in up to $56 \%$ of cases $^{24,25}$. Immunological mediated manifestations are also found in HIV-positive patients, such as glomerulonephritis, the presence of the 
rheumatoid factor, Roth spots and Janeway lesions.

Diagnosis, just as in an HIV-negative patient, is based on clinical manifestations, cultures and echocardiography. Staphylococcus is the most common agent (present in more than $70 \%$ of cases), followed by Streptococcus and Haemophilus ${ }^{23-26}$. Endocarditis caused by fungi and other bacteria such as Salmonella, which are more likely to cause bacteremia and endocarditis in these patients, has been also observed. Chart II describes the causes of infectious endocarditis in HIV patients.

Treatment of endocarditis in HIV-positive patients is no different from that provided to the general population. Long-term antibiotic therapy is indicated, as well as the

Chart II - Causes of infectious endocarditis in HIV-
infected patients. The HACEK Group: Haemophilus
parainfluenzae, haemophilus aphrophilus,
Actinobacillus actinomycetemcomitans,
Cardiobacterium hominis, Eikenella
corrodens and Kingella kingae. MRSA:
$\quad$ Methicilin-resistant S. aureus
Staphylococcus aureus (75\%)
Streptococcus viridans (20\%)
Staphylococcus epidermidis
Streptococcus pneumoniae
Haemophilus influenzae
The HACEK group
MRSA
Salmonella sp
Mycobacterium avium-intracelullare
Candida sp
Cryptococcus neoformans
Aspergillus fumigatus
Pseudallescheria boydii

same criteria for surgical management: unresponsive heart failure, sepsis, systemic embolization, fungus-caused endocarditis and therapeutic failure.

Another type of endocarditis found in patients with AIDS during the pre-HAART era was marantic endocarditis or nonbacterial thrombotic endocarditis ${ }^{23,24}$. In autopsy samples, it was found in $3 \%$ to $5 \%$ of patients. It affects the four valves - mainly the mitral and the aortic valves. It is marked by the presence of friable vegetation, rich in platelets over a fibrin network, with little inflammation and high rates of systemic embolization. There are no reports of this type of endocarditis in the post-HAART era.

\section{Myocardial Diseases}

Dilated cardiomyopathy secondary to HIV infection accounts for $3 \%$ to $6 \%$ of cases of dilated heart conditions $^{4,11}$. Compared to patients with idiopathic dilated cardiomyopathy, HIV-infected patients have a significantly shorter survival time (the relative risk of death due to heart failure is 5.86) ${ }^{4}$. Lipshultz et al observed a mean survival time of 101 days in patients with ventricular dysfunction and of 472 days in patients with normal heart status in the same stage of the HIV infection ${ }^{27}$.

Clinical pathological studies from the pre-HAART era show a $30 \%$ prevalence of cardiomyopathy in patients with AIDS $^{28}$. In a five-year prospective study with asymptomatic HIV patients, the incidence of dilated cardiomyopathy was 15.9/1,00029. Echocardiographic studies showed early diastolic dysfunction in up to $15 \%$ of patients with HIV infection ${ }^{30,31}$. As cardiomyopathy advances, diffuse hypokinesia, overall dilation of the chambers and systolic dysfunction are observed ${ }^{32}$. Reduced ejection fraction and thicker ventricular walls have been associated with increased mortality, which was found in a multicentric study conducted with children infected by their HIV-positive mothers. ${ }^{33}$

Etipathogenesis of dilated cardiomyopathy associated with HIV is multifactorial. HIV itself, other viral infections, myocarditis, autoimmunity, chronic inflammation, longterm immunosuppresion, endothelial dysfunction, arteritis, HIV-related encephalopathy, autonomic dysfunction, nutritional and trace element deficiencies and druginduced cardiotoxicity are involved.

Experimental studies that examined the infection caused by the simian immunodeficiency virus (SIV) in rhesus monkeys aimed to examine the pathogenesis of the myocardial injury related to retroviral infection. SIVchronic infection results in reduced ventricular systolic function and extensive coronary arteriopathy suggesting an injury mediated by immune cell response ${ }^{25}$. Approximately two-thirds of the primates infected that died because of the viral infection had cardiomyopathy. Lymphocytic myocarditis and coronary vasculopathy were found in nine of the fifteen animals in necropsy studies. In some primates, areas of coronary occlusion and recanalization related to areas of myocardial necrosis were observed, in addition to a case ventricular mural thrombus ${ }^{25}$.

HIV infection and the myocardial inflammatory process (myocarditis) related to it are the most studied causes of cardiomyopathy in HIV-infected patients. HIV-1 virions seem to irregularly infect the myocardial cells, without any direct association between the qualitative presence of the virus and myocyte dysfunction ${ }^{29}$. Necrosis of the myocardial fibers is usually minimal, with associated lymphocytic infiltrates. It is unclear how HIV-1 enters the myocytes since they do not have CD4 receptors ${ }^{25}$. Possibly, other cells such as the dendritic cells play a role not only as a reservoir, but also as antigen-presenting cells in the context of the major histocompatibility complex and activities of progressive tissue injury mediated by cytokines such as Interleukins 1 and 6 (IL-1 and IL-6) and the tumor necrosis factor alpha(TNF-a) ${ }^{41}$.

However, there is growing evidence to support autoimmunity as the main mechanism causing cardiomyopathy in HIV-infected patients ${ }^{41,42}$. Compared to patients with idiopathic dilated cardiomyopathy whose 
inflammatory infiltrates indicate a preponderance of CD4 (+) T cells and B lymphocytes, HIV-infected patients with echocardiographic diagnosis of dilated cardiomyopathy and histopathology compatible with myocarditis present more CD3 $(+)$ and CD8 $(+)$ T cells. 25,42 . The existence of an active immune process within the myocardium was suggested by findings of viral hybridization and increased expression of class I major histocompatibility complex molecules $(\mathrm{CPH}-\mathrm{I})$. As for humoral immunity, myocardial-specific anti-alphamyosin antibodies were found in $15 \%$ of HIV-positive patients, compared to a prevalence of $3.5 \%$ in control groups $^{5,25}$. In HIV-infected patients who present left ventricular dysfunction these antibodies are found in up to $43 \%$ of cases and can be a marker of ventricular dysfunction with prognostic implications. Another finding that supports the theoretical role played by autoimmunity in cardiomyopathy associated with HIV is the therapeutic response of patients with heart failure to immunoglobulins, which act by inhibiting cardiac antibodies, competing with Fc receptors and reducing the secretion and action of inflammatory cytokines.

As myocardial dysfunction is global and not segmented when there are foci of viral infection in the myocytes, this suggests that circulating factors or cytokines play a role as co-factors in the pathogenesis of cardiomyopathy ${ }^{25,32}$. Local production of cytokines in the myocardium increases, especially IL-1 and TNF-a. Viral infection as a stimulator of cytokines such as IL-1 and TNF-a is more likely to cause myocarditis and myocardium damage than isolated viral damage ${ }^{35,41,42}$. TNF-a has a negative inotropic effect by changing the hemostasis of intracellular calcium and probably by inducing the synthesis of nitric oxide, which also reduces myocardial contractility. Myocardial biopsies of patients with cardiomyopathy related to HIV have shown a higher intensity of markers of TNF-a and inducible nitric oxide synthase when compared to individuals with idiopathic cardiomyopathy ${ }^{41}$.

Dysfunction and activation of the vascular endothelium have been described in HIV infection ${ }^{42}$. Circulating markers of endothelial activation such as blood procoagulants and cell adhesion molecules are found less often in these patients. These findings occur because of the secretion of cytokines as a response to the activation of mononuclear cells or to a viral infection in the tunica adventitia or a response to the effects of the viral proteins gp 120 and Tat in the endothelium. Endothelial cells that have been injured and activated can cause tissue damage, inflammation and remodeling, accelerating the development of cardiovascular disease. The same mechanism of endothelial dysfunction, changes in leukocyte adhesion and arteritis can stimulate atherogenesis and eventually ischemia and myocardial injury.

Several studies reveal that HIV-infected patients with encephalopathy have a greater probability of dying from heart failure than patients without encephalopathy ${ }^{32,35,43}$. HIV may remain in the reservoir cells in the myocardium and in the cerebral cortex even after antiretroviral treatment. These cells hold HIV on their surfaces for extended periods of time and may chronically release cytokines (TNF-a, IL-6 and endothelin-1), contributing to chronic and progressive tissue damage in both systems, regardless of HAART ${ }^{32,35}$.

HIV infection can be associated with changes in the autonomous nervous system, especially in the advanced stages of the disease. $5 \%$ to $77 \%$ of patients suffered changes in cardiovascular autonomic reflexes according to the definition of the complication. This can cause orthostatic hypotension, syncope and cardiopulmonary arrest during invasive procedures ${ }^{25,32}$. The cause is unclear, although it is known that HIV is neurotropic and that it has been isolated in the peripheral neural tissue. Actually, one of the mechanisms suspected in relation to ventricular dysfunction is reduction of myocardial sensitivity to betaadrenergic stimulus.

Nutritional deficiencies are commonly observed in HIV infection, especially in more advanced stages of the disease. They make left ventricular dysfunction more probable 25,39 . Malabsorption and diarrhea promote fluid and electrolyte disorders and nutritional deficiencies ${ }^{44}$. Trace element deficiencies have been directly or indirectly related to cardiomyopathy ${ }^{44}$. In wasting patients, selenium replacement restores ventricular function and reverts cardiomyopathy ${ }^{39}$. A selenium deficiency has been shown to exacerbate the virulence of agents that induce myocarditis ${ }^{39}$. Deficiencies of thyroid hormones, vitamin B12, carnitine and growth hormones have been described in infected patients, related to left ventricular dysfunction 25,32,39.

Drug-induced cardiotoxicity in HIV-infected patients has been a highly controversial issue, especially due to the association between zidovudine and dilated cardiomyopathy. There is evidence that zidovudine is related to diffuse destruction of ultrastructures and inhibition of mitochondrial DNA replication, resulting in lactic acidosis that contributes to myocardial dysfunction ${ }^{34,38}$. However, no direct clinical relationship has been proved connecting exposure to reverse transcriptase inhibitors and induction of ventricular dysfunction. Other cardiotoxic drugs that have been used for a long time to treat this population are doxorubicin (to treat Kaposi's sarcoma and lymphoma), interferon-alpha, phoscarnet, cotrimoxazole, pentamidine and ganciclovir. Toxic agents with a high prevalence of use in this population, such as alcohol and cocaine, are aggressive agents with respect to the myocardium and are believed to aggravate ventricular dysfunction in these patients ${ }^{25,32}$.

Dilated cardiomyopathy is a late event in HIV infection, usually associated with reduced CD-4 levels. It is related to prognosis because it is associated with high mortality rates. Pathological findings show endocardial fibrosis and mural thrombus, especially at the apex, histological evidence of myocardial hypertrophy and degeneration with 
increased interstitial and endocardial fibrillar collagen. These findings are probably related to evidence of myocarditis. In a prospective study with 952 asymptomatic, HIV-infected patients, echocardiographic diagnosis of dilated cardiopathy was observed in 76 $(8 \%)$ of patients, with an annual incidence of 15.9 / $1,000^{29}$. All patients with echocardiographic confirmation were submitted to myocardial biopsy, and myocarditis was present in $63(83 \%)$ of the patients. Thirty-six individuals (57\%) presented positive hybridization signals for HIV. In some cases, coinfection with another virus - coxsackie, cytomegalovirus and Epstein-Barr was observed ${ }^{29}$.

Dilated cardiomyopathy associated with HIV infection is a clinical and echocardiographic finding ${ }^{27,28}$. Clinically, patients are similar to non-infected individuals and in some cases the echocardiographic examination can detect the infection while the patient is still in the asymptomatic phase, usually with isolated diastolic dysfunction ${ }^{30,31}$. Recommendation of the echocardiogram as a routine and screening measure in HIV-positive patients is unclear. The benefits of early diagnosis, at the initial stages of the disease, are indisputable; however, the cost-effectiveness of the procedure has not been well established. In general, as shown by studies, dilated cardiomyopathy affects patients during the advanced stage of the HIV infection. Thus the echocardiogram is well indicated for patients in which there is clinical suspicion of HIV infection or when the CD4 count is below 200 25,29,32.

Endomyocardial biopsy is another method to diagnose dilated cardiopathy whose objective is to establish the etiology and the prognosis, but its low sensitivity and risks related to the procedure limits its use to highly experienced centers and in the protocols of clinical trials. The Italian group, similar to the Instituto do Coração, recommend endomyocardial biopsy in every systolic dysfunction case associated with HIV infection, which has produced varied findings of viral myocarditis, reactivation of Chagas' disease (fig. 1), cardiac fungal infections and toxoplasmosis, many times with a satisfactory response to specific therapies.

Management of dilated cardiomyopathy related to HIV is similar to that provided to manage the idiopathic form of the disease. Because of the small number of prospective studies specifically directed to this population, management is based on results obtained in HIV-negative patients, observing some particular characteristics. In spite of the recommendation to use converting enzyme inhibitors and betablockers, there may be adverse effects in some cases in patients with reduced systemic vascular resistance because of dehydration, diarrhea or infection. Patients with myocarditis are more sensitive to digoxin and should be monitored. The use of immunosupressors is controversial in this population and promising positive results were observed in children with immunoglobulins given intravenously ${ }^{45}$.

\section{Pulmonary Hypertension}

Pulmonary hypertension was found in HIV-positive patients. Its prevalence is $1 / 200$ cases, compared with $1 /$ 200,000 cases in the general population ${ }^{46-50}$. Its detection is often associated with pulmonary infections, use of intravenous drugs, transfusion of factor VIII to hemophilic patients, venous thromboembolism, heart failure and the presence of HLA-DR6 and HLA-DR52 ${ }^{46,47}$. It affects approximately $0.5 \%$ of hospitalized patients with AIDS.

Some studies revealed precapillary muscular pulmonary artery, arteriole medial hypertrophy, fibroelastosis, and eccentric intimal fibrosis without direct viral infection of pulmonary artery cells ${ }^{48,49}$. These findings suggest release of mediators from infected cells and probably cytokine-mediated injury.

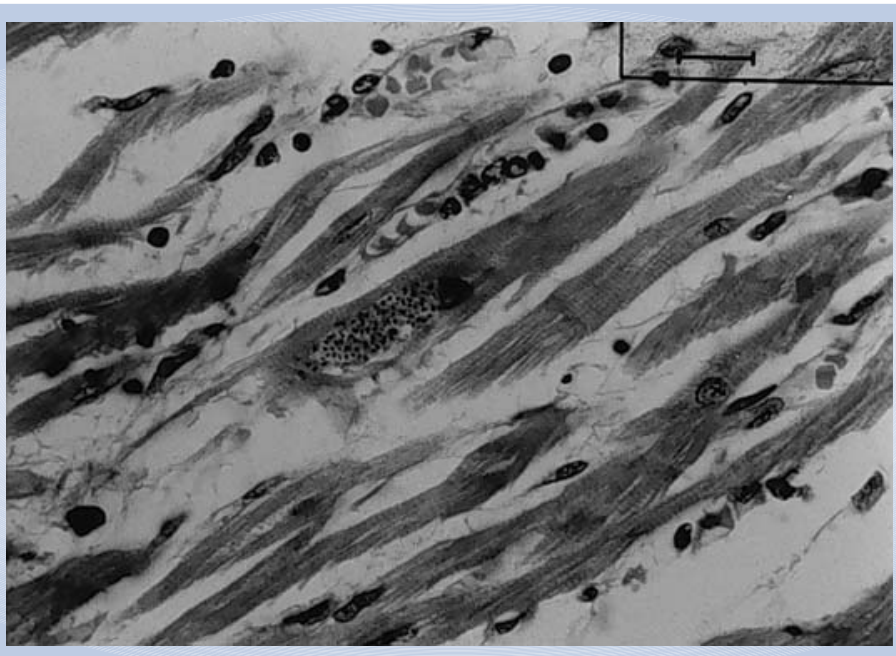

Fig. 1 - Nest of T.Cruzi amastigotes in patient with reactivation of Chagas' disease. Provided by the University of Chicago Press. Sartori AM, Lopes $\mathrm{MH}$, Caramelli B et al, Concomitant occurrence of acute myocarditis and reactivated Chagas' disease in a patient with AIDS. Clin Infect Diseases 1995; 21(5): 1297-9 
Little is known regarding the pathogenesis of primary pulmonary hypertension, but it seems to be multifactorial. However, in some HIV-positive patients, primary pulmonary hypertension is described without the presence of any predisposing factors. It is suggested that HIV itself causes endothelial injury and release of vasoconstrictive mediators such as endothelin-1, interleukin-6 (IL-6), and the tumor necrosis factor alpha in the pulmonary arteries. HIV is often identified in the alveolar macrophages in histological tets ${ }^{47}$. These macrophages release TNF- $\alpha$, free radicals and proteolytic enzymes in response to the infection. Lymphokines also seem to contribute to the endothelial proliferation observed in pulmonary hypertension since they promote leukocyte adhesion in the endothelium. Activation of $\alpha$ 1 adrenergic receptors and genetic factors (increased frequency of HLA-DR 6 and DR 52) have also been related to its pathogenesis ${ }^{47,50}$.

The symptoms and prognosis of patients with right ventricular dysfunction due to pulmonary hypertension are related to the severity of the hypertension. The picture can vary from the absence of symptoms to advanced heart failure and cor pulmonale. According to the Swiss HIV Cohort study, HIV-positive patients with pulmonary hypertension have their survival shortened when compared to non-infected patients (1.3 years vs. 2.6 years $)^{51}$.

Management with anticoagulant and vasodilating agents should consider possible drug interactions, especially with anticoagulants. There is no data to justify the wide use of vasodilating agents. Epoprostenol is used only in the most severe patients due to its high cost, need for venous infusion and increased risk of infection. To date, the effects of HAART on the incidence and clinical outcome of pulmonary hypertension and its treatment is unknown.

\section{HIV INFECTION AND}

\section{ATHEROSCLEROSIS}

Morbidity and mortality monitoring of HIV-infected patients naturally exposes them to degenerative-chronic processes such as atherosclerosis that were not manifest in the past given the early mortality of the disease. Furthermore, predisposition to atherosclerosis is also a consequence of cumulative exposition to the virus itself and important metabolic changes secondary to the antiretroviral treatment. Given this, an alarming incidence of cardiovascular and cerebrovascular events would not be surprising. Thus, this topic is still subject for further discussion.

\section{Metabolic changes}

Although the main focus on the relationship between AIDS and metabolic changes is on the side effects of antiretroviral treatment, studies from the pre-HAART era established that the HIV infection itself causes a more unfavorable lipid profile, mainly hypertriglyceridemia and low HDL-cholesterol levels ${ }^{52}$. Constans et $a^{53}$ even observed prognostic implications of these changes: the lower the CD4 lymphocyte count the higher the level of triglycerides and the lower the HDL-cholesterol levels. The pathophysiology of this association is not clear, although the pathways by which antiretroviral treatment, especially protease inhibitors, enhances this lipid disorder and affects other related to it, such as increased insulin resistance, diabetes mellitus, lipodystrophy and centripetal obesity are better understood.

Carr et $\mathrm{al}^{54}$ proposed a theory based on the structural homology finding between the catalytic site of HIV protease and important human proteins in lipid metabolism (CRABP-1: cytoplasmic retinoic acid binding protein I and the LRP: LDL receptor related protein) in such a way that protease inhibitors would also inhibit important steps of human metabolism. Eventually, protease inhibitors would determine interruption of retinoic acid metabolization and reduced PPAR-y (peroxisome-proliferator-activated receptor type gamma) activity. PPAR-y plays a key role in the differentiation of adipocytes and apoptosis of these cells, in addition to improving peripheral sensitivity to insulin. The final results of these effects are increased release of lipids in the blood flow and hypertriglyceridemia.

LRP inhibition, in turn, results in lower uptake of triglycerides by the liver and also less cleavage of triglycerides to fatty acids and glycerol that should occur because of the activity of the endothelial LRP-LPL (lipoproteic lipase) complex. Hypertriglyceridemia would be responsible for increased insulin resistance, which in susceptible individuals can promote the development of type II diabetes mellitus. Inhibition of the of cytochrome P450 3A enzyme, a step shared with protease inhibitors and retinoic acid metabolism, would also contribute to this metabolic dyscrasia.

\section{Epidemiology of cardiovascular events and risk factors for atherosclerosis}

Initially, the association between HIV infection and cardiovascular disease was inferred based on case reports of young HIV-positive patients that suffered an acute myocardial infarction, and mainly pathological findings in necropsy studies, with evidence of obstructive disease in the coronary arteries of patients without the usual risk factors for atherosclerosis ${ }^{55}$. Immuno-histochemical studies provided objective documentation of the presence of HIV in coronary arteries impaired by inflammation and atherosclerotic obstruction ${ }^{56}$. A direct association between HIV infection and the presence of coronary arteritis has been suggested, without ruling out classical atherosclerotic pathophysiology regardless of the low prevalence of risk factors in the patients studied. 
With the increasing emergence and use of aggressive antiretroviral treatment and its indisputable impact on lipid and glucose metabolism, studies with growing number of cases seek to correlate HIV infection with cardiovascular disease, and cardiovascular disease with antiretroviral treatment and cardiovascular risk factors. In 2000, Rickerts et al retrospectively studied the incidence of infarction in 4,993 patients with HIV. Although the absolute number was small, a significant increase in the infarction rate after exposure to HAART was observed ${ }^{57}$ (table I). After two years, Holmberg et al confirmed the same findings among a population of 5,672 HIV-positive patients between 1993 and 2002, showing evidence of a significant increase of the incidence of infarction after 1996, the year HAART was introduced ${ }^{58}$. However, the authors already emphasized the participation of risk factors such as smoking and dyslipidemia.

It was also in 2002 that Klein et al retrospectively examined 4,159 HIV-positive men. During 5.5 years of observation 72 cardiovascular events were described, 47 of them of myocardial infarction ${ }^{59}$. The authors did not observe the impact of exposure to antiretroviral therapy in the incidence of cardiovascular events, but their incidence in HIV- infected patients was greater than that observed among the 39,877 non-infected men in the control group $(4.86 \times 3.69$ per 1,000 persons-year; $p=$ $0.003)$. As for risk factors, a higher prevalence of dyslipidemia and smoking was observed among HIVpositive patients, but with a lower prevalence of diabetes and hypertension compared to the control group.

David et al studied the risk profile of sixteen HIVinfected patients $(1.7 \%$ of the total 951 infected patients) with confirmed diagnosis of coronary artery disease. Their findings showed that $81 \%$ of them were smokers, 63\% had hypertension, 50\% had dyslipidemia and $31 \%$ had family history of cardiovascular diseases ${ }^{60}$. The authors compared the characteristics of these patients with the characteristics of 32 HIV-positive individuals without evidence of coronary artery disease (CAD). They showed that the prevalence of risk factors was significantly higher in those with evidence of CAD with no association between exposure to protease inhibitors and increased risk.

The largest number of cases was published in 2003. Bozzette et al retrospectively studied 36,766 HIV-infected patients undergoing treatment between 1993 and 2001 for general mortality, specific mortality due to cardiovascular and cerebrovascular events and their hospitalization rates ${ }^{61}$. The only expressive changes observed during this period were an important reduction in general mortality rate and a significant increase in antiretroviral therapy, especially after 1995 and 1996. There was no increase in the incidence of cardiovascular or cerebrovascular events concomitant to improved survival rates. Although the authors did not specify the profile of classical risk factors for atherosclerosis in this population, they relate that $23.9 \%$ of patients had already been previously treated for diabetes, hypertension or smoking, and $6.6 \%$ of them already had been diagnosed for vascular disease. The authors also observed the interesting growth in the use of lipidlowering drugs from 140 patients making use of some medication available to control dyslipidemia in 1995 to 2,417 patients in 2001 .

Currier et al conducted a study, also retrospective, including 28,513 patients with HIV and 3,054,696 noninfected patients, with the objective of determining the specific incidence of coronary artery disease by age groups of HIV-positive men and women compared to non-infected individuals ${ }^{62}$. Mean observation time was 2.5 years for HIV-positive patients and 2.64 years for HIV-negative patients. HIV-infected patients had 1,360 cardiovascular events, whereas the control group had 234,521 . When these events were studied according to gender and age group, HIV infection proved to be an important risk marker for men younger than 34 and for women younger than 44 . This association was not very strong in older age groups for both genders, but there was a curious finding in some of these lower risk brackets among HIV-positive patients: a relative risk of CAD in men between 55 and 64 years (infected vs. non-infected) of $0.60(0.51-0.71 ; p<0.0001)$. The use of antiretroviral therapy was associated with increased risk of coronary disease (relative risk of 2.06; $p<0.001$ ) for patients younger than 33. The authors observed a profile with higher risk among HIV-infected patients with a progressive increase in prevalence of cardiovascular risk factors in older age groups.

In November, 2003 data from the DAD (Data Collection on Adverse Events of Anti-HIV Drugs) were published with evidence of positive correlation between the duration of exposure to antiretroviral therapy and the risk of myocardial infarction ${ }^{63}$. A prospective study examined 23,468 patients with HIV, with mean follow-up of less than 2 years and 126 recorded cases of myocardial infarction. Only $55 \%$ of the 126 cases met the definitive criteria for this condition according to the requirements of the MONICA ${ }^{64}$ project. The absolute rate of events was low, corresponding to 3.5 events per thousand personsyear. However, each year of exposure to combined antiretroviral therapy determined a $26 \%$ increase in the relative risk of myocardial infarction during the first four to six years of exposure. In the same cohort of patients, the prevalence of traditional risk factors for coronary disease was high: smoking: $56.2 \%$; dyslipidemia: $45.9 \%$; hypertension: $7.2 \%$; diabetes: $2.8 \%$. Old age, a history of smoking, male gender and early diagnosis of cardiovascular disease are independent predictive factors of myocardial infarction ${ }^{63}$.

Varriale et al conducted a 3-year prospective study with 690 hospitalized HIV-infected patients ${ }^{65}$. There were 29 cases of myocardial infarction during the study, with 
an incidence of $1 / 100$ patients-year of observation, similar to what is found in the general North-American population. The cardiovascular risk profile of these patients showed that $55 \%$ smoked, $21 \%$ had dyslipidemia, $14 \%$ had hypertension, $14 \%$ had family history of early CAD onset and $21 \%$ did not present any risk factor. The mean age of infarcted patients was 46 years ( \pm 10 y.), $66 \%$ received a protease inhibitor, and although $79 \%$ of them had at least a risk factor for atherosclerosis, the association between them was low in most cases.

Matetzky et al ${ }^{66}$ conducted a prospective study with 24 patients with AIDS hospitalized with a diagnosis of myocardial infarction between 1998 and 2000. Mean follow-up was fifteen months. Comparing the HIVpositive patients to 48 infarcted HIV-negative patients in the control-group, the authors did not observe significant differences between the prevalences of diabetes, hypertension, smoking, dyslipidemia or family history of CAD, which suggested the direct impact of retroviral infection in the disease. However, the noninferiority of the risk profile reinforces the importance of traditional factors in the etiopathogenicity of coronary disease in HIV-infected patients. In this group, $58 \%$ of the patients smoked; $58 \%$ had dyslipidemia; $50 \%$ had a family history of early CAD; $29 \%$ had hypertension and $12 \%$ had diabetes. Furthermore, the authors conducted a comparative study regarding morbidity and mortality in the short and in the medium terms, showing that HIV-positive patients had a benign nosocomial outcome, but that morbidity was higher after discharge: a larger rate of reinfarction ( $20 \%$ vs. $4 \%$; $p=0.07$ ) and a higher recurrence of symptoms (45\% vs.11\%; $p$ $=0.007)$, but without an increase in mortality rate $(0$ vs. $4 \% ; p>0.99$ ). No difference was observed in the angiographic characteristics regarding damage to the coronary arteries.

Finally, Hsue et al retrospectively assessed the risk factors and the clinical outcome of 68 HIV-infected patients hospitalized between 1993 and 2003 due to unstable angina or myocardial infarction. They compared their characteristics to a control group made up of 68
HIV-negative individuals with a diagnosis of acute CAD ${ }^{67}$. Prevalence of smoking ( $46 \%$ vs. $28 \%$; $p=0.003$ ) and low HDL-cholesterol ( $35 \pm 12$ vs. $41 \pm 9 ; p=0.005)$ was higher in patients with AIDS and they were younger as well $(50 \pm 8$ vs. $61 \pm 11$ years; $p<0.001)$. However, prevalence of diabetes and dyslipidemia was higher in the control-group. The general risk score was assessed by the TIMI score ${ }^{68,69}$. It was higher in the control-group, whose angiograms showed a larger area of coronary artery damage. However, the rate of restenosis with clinical manifestations was higher in HIVinfected patients than in control subjects that had been submitted to angioplasty with a stent ( $50 \%$ vs. $18 \%$; p $=0.078$ ). Overall, 29 angioplasties were performed in HIV-positive patients, with the use of stents in 22 of these procedures. In the control group, eleven angioplasties with stents were performed and ten used only a balloon-tip catheter.

A recent study sought to objectively establish the risk relationship between cardiovascular disease and the use of antiretroviral therapy ${ }^{70}$. The sample consisted of 721 subjects divided into three paired groups based on age and gender; 219 patients were HIV- positive and used HAART, 64 HIV-positive patients who did not receive HAART and 438 control subjects (HIV-negative). Cardiovascular risk was estimated using the Framingham risk score. This study showed that the prevalence of coronary risk estimated at greater than $20 \%$ in ten years was twice as high in HAART-treated patients than in the control-group ( $11.9 \%$ vs. $5.3 \%$; $p=0.004$ ). HIV-positive patients that had not received HAART treatment had an estimated risk greater than $20 \%$ in ten years of $6.3 \%$, without a significant difference when compared to the HIV-positive patients receiving HAART $(p=0.25)$ or to the control group ( $p=0.76$ ). Among the risk factors observed, the prevalence of smoking was higher in HIVpositive patients than in the control group $(54.5 \%$ vs. $30.1 \%$ ), along with higher levels of total cholesterol and lower levels of HDL-cholesterol.

In general, primary and secondary prevention of cardiovascular disease initially considers only the exposure to risk factors, but the need of a more precise definition

Table I - Epidemiological studies on cardiovascular disease and AIDS

\begin{tabular}{|c|c|c|c|c|}
\hline Author/year & Type & $\mathrm{n}$ & Period & Finding \\
\hline Rickerts/ 2000 & Retrospective & 4,993 HIV + & 1983-1998 & $\begin{array}{l}\text { Increased incidence of } \mathrm{MI} \text { after HAART } \\
(0.86 / 1,000 \cdot 3.41 / 1,000 \text { persons-year) }\end{array}$ \\
\hline Holmberg/ 2002 & Retrospective & $5,672 \mathrm{HIV}+$ & 1993-2002 & Increased incidence of MI after HAART \\
\hline Klein/ 2002 & Retrospective & 4,159 HIV+39,877 HIV - & 1996- 2001 & $\begin{array}{l}\text { Increased hospitalization rate because of CAD } \\
\text { ( } 4.86 \text { vs. } 3.69 / 1,000 \text { persons-year; } p=0.003 \text { ) } \\
\text { Non-related to HAART }\end{array}$ \\
\hline Bozzette/ 2003 & Retrospective & 36,766 HIV+ & 1993-2001 & $\begin{array}{l}\text { Increase survival without increase in the incidence } \\
\text { of cardiovascular events }\end{array}$ \\
\hline Currier/ 2003 & Retrospective & 28,513 HIV+3,054,696 HIV- & $1994-2000$ & $\begin{array}{l}\text { Increased risk for CAD Men }<34 \text { years and } \\
\text { women }<44 \text { years }\end{array}$ \\
\hline DAD/ 2003 & Prospective/Observational & 23,468 HIV+ & 1999-2002 & $\begin{array}{l}\text { Low incidence of MI.(3.5/1,000 patients-year) } \\
\text { Related to the length of use of HAART therapy }\end{array}$ \\
\hline
\end{tabular}


of populations at risk led to the implementation of tracking exams to identify atherosclerosis before its clinical manifestations known as subclinical atherosclerosis which has been proven to be related to a higher incidence of future events. Among the exams performed, an ultrasound of the carotid and femoral arteries to detect thickening of the intima-media complex in these arteries, endothelial function tests and, more recently, detection of calcium in the coronaries should be highlighted. In the specific context of HIV infection, an increased prevalence of endothelial function, mainly among patients that receive protease inhibitors, as well as an increased prevalence of the thickening of the intima/media layers of the carotids have already been shown ${ }^{71}$. Recently, in addition to increased thickening of the media/intima layers of the carotids of the patient when compared to the control group, faster progression of this thickening was observed within one year ${ }^{72}$

\section{Dyslipidemia management in patients HIV-positive}

The Framingham study showed that control of dyslipidemia reduces the risk of cardiovascular diseases both as primary and secondary prevention. There are no conclusive epidemiological studies on this issue specifically among HIV-positive individuals. However, increased survival of these patients is related to the adoption of measures to reduce real cardiovascular risk. The Brazilian Society of Cardiology (SBC) was the first to include a specific topic regarding management of HIVpositive patients in the Brazilian Guidelines for Dyslipidemias and Atherosclerosis Prevention in 2001. The SBC recommends measuring the lipid profile at the beginning of follow-up: if results are normal and if protease inhibitors are not given the test should be repeated one month later and then every three months. Treatment of dyslipidemic HIV-infected patients should follow the guidelines established for the general population after overall assessment of other risk factors. Drug-based treatment should be introduced with caution and only if dyslipidemia persists after nonpharmacological management ${ }^{73,74}$.

However, the prescription of lipid-lowering agents can add complications to complex antiretroviral combinations $^{75}$. Some options for the pharmacological management of dyslipidemia have been suggested, such as changing the regimen of antiretroviral treatment by replacing the current protease inhibitor with a different one or with a non-nucleoside reverse transcriptase inhibitor. But these theoretically favorable changes have not produced considerable benefits in clinical trials. Furthermore, there is the possibility that they may change the characteristics of the chronic viral infectious process such as resistance and serotyping ${ }^{76,77}$.

The drugs most commonly used to treat HIV-positive patients with dyslipidemia are the same used to treat the general population: statins, fibrates and nyacin. Recommendations from AIDS study groups use the NCEP Panel III to manage dyslipidemia ${ }^{74}$. Guidelines are based on the patient's overall risk analysis and on the LDLcholesterol fasting levels.

Statins: Except for pravastatin and rosuvastatin, most statins are metabolized by the cytochrome P450 3A4 isoenzyme that is inhibited by current protease inhibitors. Therefore, administration of statins with protease inhibitors can increase blood statin to dangerous levels, possibly causing musculoskeletal toxicity and other adverse effects ${ }^{73-77}$. Statins must be given initially in low doses with frequent monitoring due to potential interactions. In clinical practice, some authors used atorvastatin safely in this population, a fact confirmed in our experience ${ }^{76,77}$. Consequently, in theory, the safest statins for use with protease inhibitors are pravastatin, atorvastatin and rosuvastatin. They are the drugs of choice to treat subjects with hypercholesterolemia, in addition to being effective for treating hypertriglyceridemia, especially atorvastatin and rosuvastatin.

Fibrates: Fibrates are the first choice to manage combined dyslipidemia in HIV- infected patients, the most commonly observed change in this population ${ }^{74,77}$. The long-term effects of the combination of fibrates with protease inhibitors are unknown. Gemfibrozil is well tolerated by HIV-positive patients and its interaction profile shows that it can be used. A study showed a $30 \%$ reduction in total cholesterol and a $60 \%$ reduction in trygliceride levels when atorvastatin and gemfibrozil were given to patients with HIV77. Recommendations favor the use of gemfibrozil or fenofibrate in this population ${ }^{73,74}$.

Nyacin: Nyacin reduces LDL-cholesterol and tryglicerides and increases HDL-cholesterol. However, side effects such as flushing, itching, high glucose level and especially liver toxicity do not recommend it as first choice agent to treat HIV-positive subjects.

Other agents: Cholestyramine and colestipol are not recommended because they interfere with the bioavailability of protease inhibitors and because they increase trygliceride levels ${ }^{77}$. Glitazones, PPAR-g receptor activators, did not prove to be useful for managing dyslipidemia in these patients. Metformin proved to be effective in reducing tryglicerides, but may increase the risk of lactic acidosis, especially in the presence of continuous use of reverse transcriptase inhibitors ${ }^{77}$. Omega-3 fatty acids are useful for treating hypertriglyceridemia in HIV-positive patients, but they have not been assessed in patients that had been given protease inhibitors ${ }^{77}$. Another frontier to be explored is the pursuit of protease inhibitors with a lower atherogenic profile and fewer interactions with lipid lowering drugs. Atazanavir a powerful and effective protease inhibitor has been recently approved. It is been suggested that it has a lower incidence of metabolic side effects in patients treated for 108 weeks $^{77}$. 
In patients that switched from nelfinavir to atazanavir, lipid levels returned to those found before treatment with nelfinavir. However, a careful analysis reveals that these studies have similar methodological deficiencies, including inadequate sample size, absence of fasting or alcohol abstinence before collecting blood for lipid profile analysis and non-correction of potential misleading factors such as diabetes or diet. In our opinion, no preferred antiretroviral regimen with the objective of lower cardiovascular risk has been satisfactorily defined taking into account the major importance of other risk factors related to dyslipidemia in this specific population combined with the limitations of the studies available.

To conclude, given the characteristics of the cardiovascular risk profile of this population, nonpharmacological interventions seem to have the most important effect in preventive treatment of HIV-infected patients. These patients should be counseled to control the risk factors related to lifestyle issues such as stop smoking, follow a diet, be active, and control high blood pressure and diabetes ${ }^{74}$.

\section{AIDS IN CHILDREN}

\section{Epidemiology}

In spite of all efforts to prevent maternal-fetal transmission of the HIV virus in Brazil, it is still common. In addition, advances in controlling the disease and its complications have resulted in progressive reduction of its lethality during childhood. This results in a significant increase of infected children that need to control possible long-term complications ${ }^{78}$ (graphic 1).

International data have shown a significant decline in child mortality due to AIDS and an overall increase in survival of these children. But although there is a reduction of infection-related deaths, there is a secular trend of discreet, but progressive, increase of proportional mortality due to cardiac causes in children affected by AIDS ${ }^{79,80}$.

When the impact of cardiovascular complications on mortality rate in children with AIDS is studied, they are seen to indicate a poor prognosis. Studies conducted with children that died showed that cardiomegaly, pericardial effusions and systolic or diastolic ventricular dysfunctions were frequently present. However, clinical manifestations of congestive heart failure, increased heart rate or systemic arterial hypertension seem to be independent predictive factors of mortality ${ }^{81-84}$.

Cardiovascular complications of AIDS in children are highly common. These complications have been shown to affect $25 \%$ of ten-year old children and there is direct relationship between the prevalence of these complications and the length of the disease ${ }^{85-87}$.

Clinical signs in children with heart complications due to AIDS are not always present ${ }^{88}$, but there are some correlations between clinical picture and heart conditions. Rapidly progressive forms of AIDS in children are usually associated with increased heart and respiratory rates and fractional shortening of the left ventricle ${ }^{89}$. There is evidence of a negative association between nutritional status and left ventricular mass, suggesting increased sympatic tone in the more severely affected patients ${ }^{44}$. The presence of encephalopathy, in turn, seems to be associated with progressive fractional shortening of the left ventricle ${ }^{33}$.

Pulmonary hypertension also seems to be a frequent complication in the chronic situation of children with AIDS. It seems to be related to recurrent bronchopulmonary infection ${ }^{90,91}$ and the hystopathological injury most commonly found is plexogenic pulmonary arteriopathy ${ }^{92}$.

Graphic 1 - Number of new AIDS cases and deaths provoked by it in Brazilian children and adolescents, from 1981 to 2003. Source: Datasus
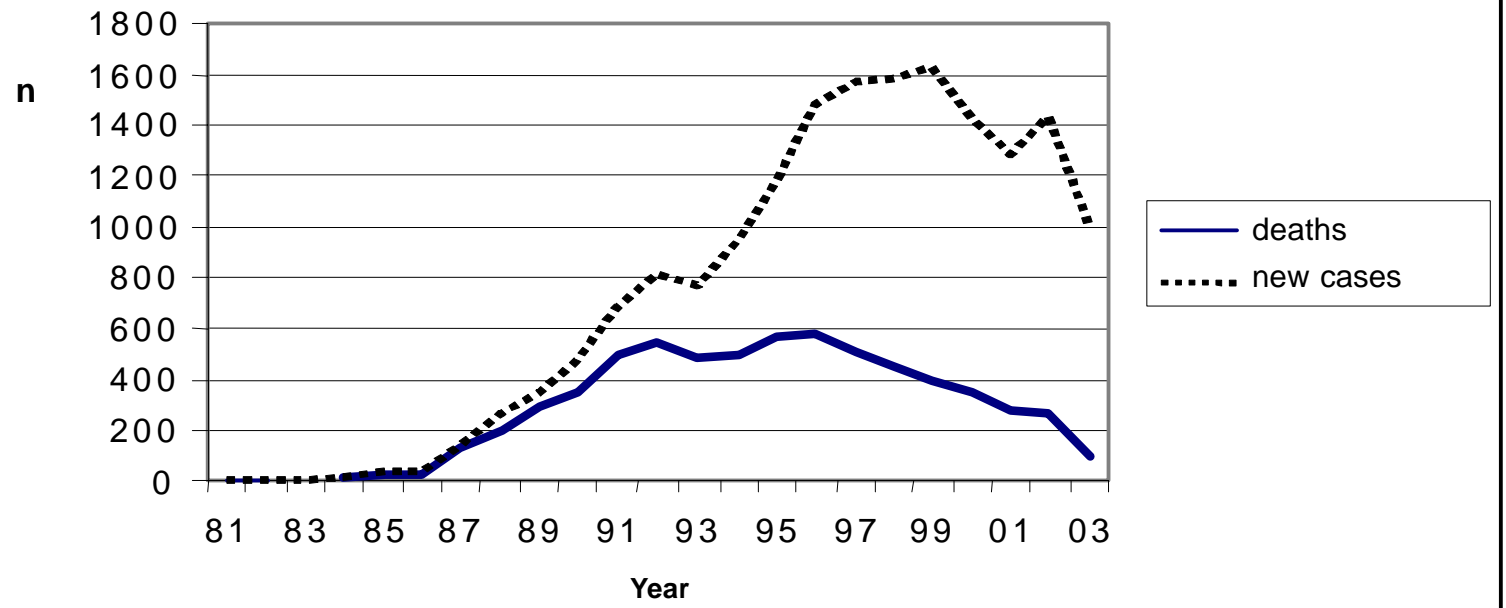
There is a negative relation between $C D 4+T$ lymphocyte levels and systolic function of the left ventricle in the initial stages of the disease. As it advances, this association becomes weaker ${ }^{33}$. HIV-positive patients with normal levels of serum IgG or undergoing replacement treatment usually have normal ventricular function and structure, suggesting immunological mediation in left ventricle remodeling ${ }^{93}$. When the presence and level of dilation of the left ventricle are studied, there is a positive association between the viral and negative load with CD4+ T lymphocytes ${ }^{94}$.

In addition to direct injury of the myocardium caused by HIV, immunosuppression can result it a higher risk of myocarditis caused by other infectious agents. The genome of several viruses in the myocardium of children with advanced stage of AIDS was found. These children usually had dilated cardiomyopathy and congestive heart failure ${ }^{95}$.

There is still no consensus as to whether or not there is cardiac protection when new antiretroviral agents are used to treat children with AIDS ${ }^{82,96-98}$. However, signs of mitochondrial injury in myocytes associated with the use of these agents were found, regardless of the direct action of the infection ${ }^{99}$.

\section{AIDS in children, vascular injury and atherogenesis}

Some studies in children have shown a positive relation between HIV infection and vascular injury. Laboratory evidence shows an increase in von Willebrand and tissue plasminogen activator factors, two markers of endothelial dysfunction. It seems that their levels are directly related to the viral load, cytokines and advanced stage of the disease $^{100}$. The pathophysiological mechanism has not been fully explained, but it seems to be mediated by the synergism between HIV-1 Tat protein (released by infected cells) and TNF- $\alpha^{101}$. The dilation of the aortic root observed in HIV-infected children may also represent a manifestation of vascular lesion, perhaps caused by lymphoproliferative inflammation due to the virus ${ }^{94}$.

There is increasing concern with respect to diagnosis of endothelial dysfunction in childhood or adolescence because this is the first sign of the progression of atherosclerosis. Bonnet, studying a series of cases of 49 HIV-positive children, found significantly higher changes of artery distensibility in infected children than in the control group. This was not seen when differences related to the thickness of the intima and media layers of the carotid were studied ${ }^{102}$.

The effects of antiretroviral agents and the progress of atherogenesis have been extensively studied. This is important for infected children and adolescents who have been theoretically exposed to these effects for a longer period of time. However, if on the one hand the bloodlipid increasing effect of these agents are described as occurring at any age, on the other hand there is evidence that they can reduce the serum expression of vascular activation markers such as the soluble vascular cell adhesion molecule (sVCAM1), von Willebrand factor and the D-dimer ${ }^{104}$.

\section{The EXPerience at InCor}

In a pioneer study, we examined the changes in the lipid profile of thirty HIV-positive patients before and after providing protease inhibitors. Patients were monitored at the Outpatient unit Casa da Aids-SP and by the team of the Interdisciplinary Medical Unit at InCor. A mean increase of $31 \%$ was found in the total circulating cholesterol level $(p<0.0006$ ) and of $146 \%$ in the triglyceride level $(p<0,0001)$. In the same study, thirteen patients with persistent hypertriglyceridemia after dietary therapy received fenofibrate. A $6.6 \%$ reduction in total cholesterol level was observed ( $p=0.07$ ), as well as a significant reduction of $45.7 \%$ in the triglyceride level ( $p$ $=0.0002$ ), with no adverse effects ${ }^{104}$. More recently, we analyzed the role played by bezafibrate in treating dyslipidemia related to the use of antiretroviral therapy. We evaluated the behavior of the lipid profile before and after treatment with bezafibrate in 84 patients whose high triglyceride levels persisted after dietary therapy. A significant decrease in blood triglyceride, total cholesterol and fasting glucose levels was observed with good tolerability (graphic II)

\section{Conclusions AND PERSPECTIVES}

Throughout its twenty-year history, the human immunodeficiency virus infection epidemic has provided multiple learning lessons for science. These lessons became necessary to understand this disease and others. The difficult initial search for its etiological agent was soon replaced by perspectives related to its treatment and reduction of morbidity and mortality rates, which were attained. However, during this period, with widespread use of antiretroviral agents in powerful combinations, we were able to learn the natural history of HIV infection, the different aspects of the disease in the 1980's and the beginning of the 1990's. Due to virological control and better preservation of the immune system, opportunistic infections were replaced by clinical manifestations of the disease caused by the virus itself, thus allowing us to detect the autoimmune, inflammatory and cardiovascular diseases related to it. In this context, the adverse effects of antiretroviral agents emerged. They have contributed to an expressive morbidity, especially from the metabolic point of view.

Since patients live longer, the cardiovascular system has increased in importance and is no longer a mere observer of the patient succumbing to opportunistic infections. Furthermore, there is a series of cardiovascular risks and metabolic complications that affect them. The 
heart is affected in different ways by the disease. Involvement of the pericardium, endocardium and myocardium is recognized, ranging from asymptomatic disease to death. Studies show an increased mortality rate for patients with cardiovascular impairment, which triggers the need for intervention. Some aspects attract our attention. First, the high prevalence of smoking and the inadequate lifestyle and diet followed by these patients, which contribute to increased cardiovascular risk. The pleiotropic effect of the virus should be emphasized, from myocardial infection to metabolic disorders resulting from its presence in the body. No less important is the contribution of the adverse effects of antiretroviral agents, which negatively affect patients' metabolism, in addition to promoting significant drug interactions whenever other agents are used.

The assessment of patients with HIV with respect to cardiovascular disease demands a high level of clinical suspicion since the clinical picture is very frequently frustrating or confused with the other most commonly found diseases. Knowledge of cardiovascular manifestations in HIV infection leads to the need to implement effective measures in order to reduce the occurrence of cardiovascular diseases in this population, which can be attained by strict control of risk factors, early diagnosis of cardiopathy, adequate therapy, and, finally, the constant pursuit of antiretroviral treatment that offers less adverse effects without affecting efficacy.

The cardiologist, together with the infectious disease specialist, should contribute to reducing cardiovascular risks in HIV-positive patients, giving overall consideration to the various risk factors and strengthening recommendations regarding diet and lifestyle and, in special situations, cautiously provide combined pharmacological agents.

\section{Graphic 2 - Behavior of lipid profile and fasting glucose levels in HIV-positive patients monitored at} InCor before and after treatment with bezafibrate (BZF)

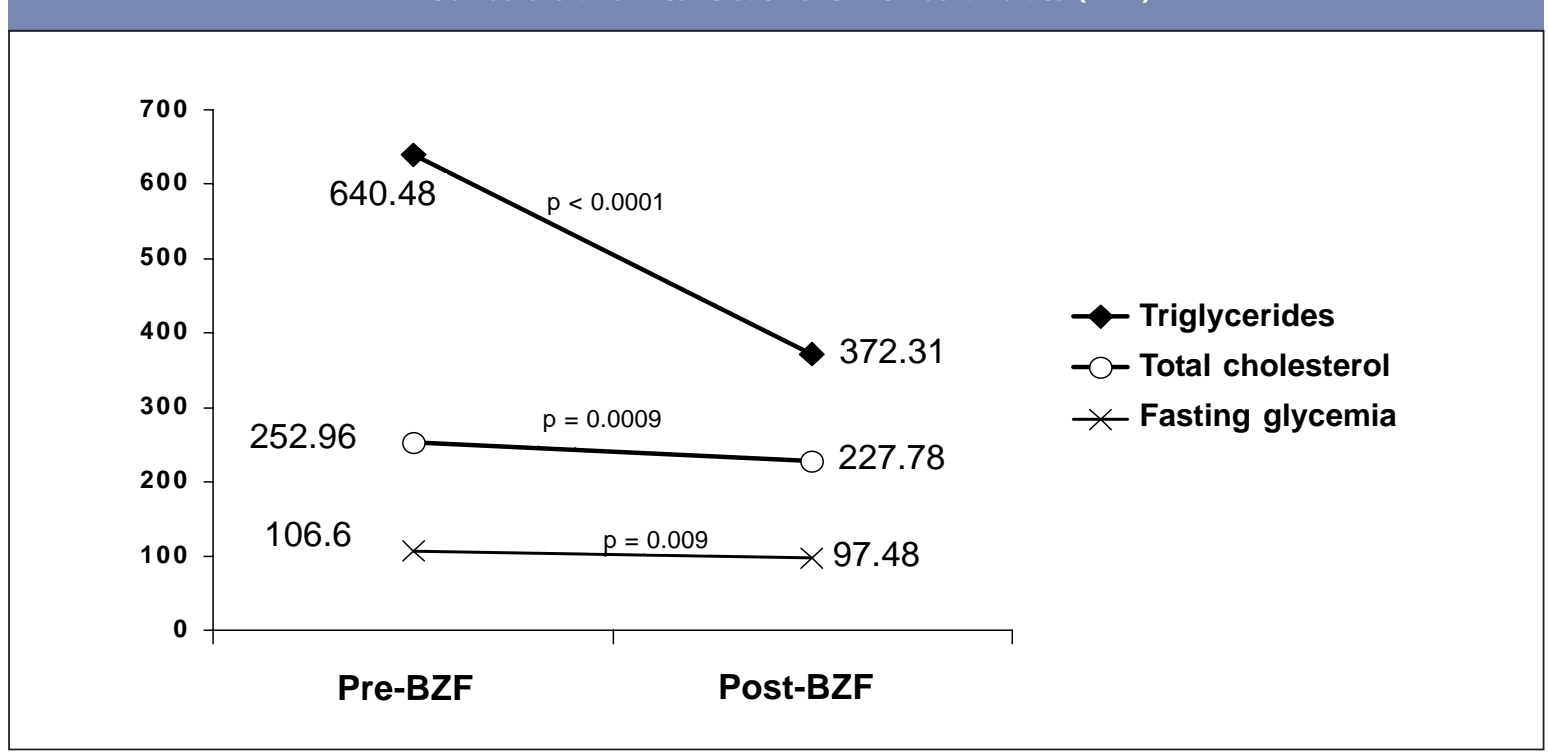

\section{REFERENCES}

1. Yunis NA, Stone VE. Cardiac manifestations of HIV/AIDS: A review of disease spectrum and clinical management. J AIDS Hum Retrovirol 1998; 18: 145-54.

2. Barbaro G. Pathogenesis of HIV-associated heart disease. AIDS 2003; 17: S12-S20.

3. Prendergast BD. HIV and cardiovascular medicine. Heart 2003; 89 (7): 793-800.

4. Barbaro G. Cardiovascular manifestations of HIV infection. J R Soc Med 2001; 94: 384-0.

5. Autran BR, Gorin I, Leibowitch M et al. AIDS in a Haitian woman with cardiac Kaposi's sarcoma and Whipple's disease. Lancet 1983; I: 767-8.

6. D'Amati G, Di Gioia CR, Gallo P. Pathological findings of HIV-associated cardiovascular disease. Ann N Y Acad Sci 2001; 946; 23-45.

7. Barbaro G, Di Lorenzo G, Grisorio B et al. Cardiac involvement in the acquired immunodeficiency syndrome. A multicenter clinicalpathological study. AIDS Res Hum Retroviruses 1998; 14:1071-7.
8. Arshad A, Bansal A, Patel RC. Cardiac complications of human immunodeficiency virus infection: diagnostic and therapeutic considerations. Heart Disease 2000; 2; 133-45.

9. Barbaro G. Cardiovascular manifestations of HIV infection. Circulation 2002; 106: 1420-5.

10. Barbaro G, Fisher SD, Pellicelli AM et al. The expanding role of the cardiologist in the care of HIV infected patients. Heart 2001; 86: 365-73

11. Rerkpattanapipat P, Wongpraparut N, Jacobs LE et al. Cardiac manifestations of acquired immunodeficiency syndrome. Arch Intern Med 2000; 160: 602-8.

12. Milei J, Grana D, Fernández Alonso G et al. Cardiac involvement in acquired immunodeficiency syndrome - a review to push action. Clin Cardiol 1998; 21: 465-72.

13. Heidenreich PA, Eisenberg MJ, Kee LL et al. Pericardial effusion in AIDS: incidence and survival. Circulation 1995; 92: 3229-34. 
14. Silva-Cardoso J, Moura B, Martins L et al. Pericardial involvement in human immunodeficiency virus infection. Chest 1999; 115: 418-22.

15. Chen $Y$, Brennessel D, Walters J et al. Human immunodeficiency virus-associated pericardial effusion: report of 40 cases and review of the literature. Am Heart J 1999; 137: 516-21.

16. Miller RF, Howling SJ, Reid AJ et al. Pleural effusions in patients with AIDS. Sex Trans Infect 2000; 76: 122-5.

17. Dal Maso L, Serraino D, Franceschi S. Epidemiology of HIVassociated malignancies. Cancer Treat Res 2001; 104: 1-18.

18. Duong M, Duboi C, Buisson M et al. Non-Hodgkin's lymphoma of the heart in patients infected with human immunodeficiency virus. Clin Cardiol 1997; 20: 497-2.

19. Gowda RM, Khan IA, Mehta NJ, Gowda MR, Sacchi TJ. Cardiac Tamponade in patients with immunodeficiency virus disease. Angiology 2003; 54 (4): 469-74.

20. Estok L, Wallach F. Cardiac tamponade in a patient with AIDS: a review of pericardial disease in patients with HIV infection. Mt Sinai J Med 1998; 65: 33-9.

21. Sanna P, Bertoni F, Zucca E et al. Cardiac involvement in HIV- related non Hodgkin lymphoma: a case report and short and short review of the literature. Ann Hematol 1998; 77: 75-8.

22. Currie PF, Sutherland GR, Jacob AJ et al. A review of endocarditis in acquired immunodeficiency syndrome and human immunodeficiency syndrome. Eur Heart J 1995; 16 (suppl B): 15-18.

23. Nahass RG, Weinstein MP, Bartels J et al. Infective endocarditis in intravenous drug users: a comparison of human immunodeficiency virus type 1-negative and-positive patients. J Infect Dis 1990; 162: 967-0.

24. Moss R, Munt B. Injection drug use and right sided endocarditis. Heart 2003; 89: 577-81.

25. Barbaro G, Fisher SD, Lipshultz SE. Pathogenesis of HIV-associated cardiovascular complications. Lancet Infect Dis 2001; 1: 115-124.

26. Barbaro G, Klatt EC. HIV infection and the cardiovascular system. AIDS Rev 2002; 4: 93-103.

27. Lipshultz SE. Dilated cardiomiopathy in HIV-infected patients. N Eng J Med 1998; 339: 1153-55.

28. Levy WS, Simon GL, Rios JC, Ross AM. Prevalence of cardiac abnormalities in human immunodeficiency virus infection. Am J Cardiol 1989; 63: 86-9.

29. Barbaro G, Di Lorenzo G, Grisorio B et al. Incidence of dilated cardiomyopathy and detection of HIV in myocardial cells of HIVpositive patients. N Engl J Med 1998; 339:1093-9.

30. Barbaro G, Barbarini G, Di Lorenzo G. Early impairment of systolic and diastolic function in asymptomatic HIV-positive patients: a multicenter echocardiographic and echo-Doppler study. Aids Res and Hum Retroviruses 1996; 12 (16): 1559-63.

31. Corallo S, Mutinelli MR, Moroni M et al. Echocardiography detects myocardial damage in AIDS: Prospective study in 102 patients. Eur Heart J 1988; 9: 887-2.

32. Barbaro G. Dilated cardiomyopathy in the acquired immunodeficiency syndrome. Eur Heart J 1999; 20: 629-30.

33. Lipshultz SE, Easley KA, Orav EJ et al. Left ventricular structure and function in children infected with human immunodeficiency virus: the prospective P2C2 HIV Multicenter Study. Pediatric Pulmonary and Cardiac Complications of Vertically Transmitted HIV Infection (P2C2 HIV) Study Group. Circulation 1998; 97 (13): 1246-56.

34. Fantoni M, Autore C, Del Borgo C. Drugs and cardiotoxicity in HIV and AIDS. Ann N Y Acad Sci 2001; 946: 179-99.

35. Lewis W. Cardiomyopathy in AIDS: a pathophysiological perspective. Prog Cardiovasc Dis 2000; 43: 151-70.
36. Currie PF, Goldman JH, Caforio AL et al. Cardiac autoimmunity in HIV related heart muscle disease. Heart 1998; 79: 599-604.

37. Grody W, Cheng L, Lewis W. Infection of the heart by the human immunodeficiency virus. Am J Cardiol 1990; 66: 203-6.

38. Herskowitz A, Willoughby SB, Baughman KL et al. Cardiomyopathy associated with anti-retroviral therapy in patients with HIV infection: a report of six cases. Ann Intern Med 1992; 116: 311-3.

39. Hoffman M, Lipshultz SE, Miller TL. Malnutrition and cardiac abnormalities in the HIV-infected patients. In: Miller TL, Gorbach S, eds. Nutritional Aspects of HIV Infection. London, UK: Arnold, 1999, 33-9.

40. Lewis W, Gupp IL, Grupp G et al. Cardiac dysfunction in the HIV-1 transgenic mouse treated with zidovudine. Lab Invest 2000; 80: 187-7.

41. Barbaro G, Di Lorenzo G, Soldini M et al. The intensity of myocardial expression of inducible nitric oxide synthase influences the clinical course of human immunodeficiency virus associated cardiomyopathy. Circulation 1999; 100: 633-9.

42. Chi D, Henry J, Kelley J et al. The effects of HIV infection on endothelial function. Endothelium 2000; 7: 223-42.

43. Barbaro G, Di Lorenzo G, Soldini M et al. Clinical course of cardiomyopathy in HIV-infected patients with or without encephalopathy related to the myocardial expression of TNF-a and iNOS. AIDS 2000; 14: 827-8.

44. Miller TL, Orav EJ, Colan SD, Lipshultz SE. Nutritional status and cardiac mass and function in children infected with the human immunodeficiency virus. Am J Clin Nutr 1997; 66 (3): 660-4.

45. Lipshultz SE, Orav EJ, Sanders SP et al. Immunoglobulins and left ventricular structure and function in pediatric HIV infection. Circulation 1995; 92: 2220-5.

46. Golpe R, Fernandez-Infante B, Fernandez Rozas S. Primary pulmonary hypertension associated with human immunodeficiency virus infection. Postgrad Med J 1998; 74: 400-4.

47. Pellicelli AM, Palmieri F, D'Ambrosio $C$ et al. Role of human immunodeficiency virus primary pulmonary hypertension: case reports. Angiology 1998; 49: 1005-1.

48. Pellicelli A, Barbaro G, Palmieri F et al. Primary pulmonary hypertension in HIV disease: a systematic review. Angiology 2001; 52: 31-41.

49. Mehta NJ, Khan IA, Mehta RN et al. HIV-related pulmonary hypertension: analytic review of 131 cases. Chest 2000; 118 : 1133-41.

50. Mesa RA, Edell ES, Dunn WF et al. Human immunodeficiency virus infection and pulmonary hypertension. Mayo Clin Proc 1998; 73 : 37-44.

51. Opravil M, Pechere M, Speich R et al. HIV-associated primary pulmonary hypertension. A case control study. Swiss HIV Cohort Study. Am J Respir Crit Care 1997; 155: 990-5.

52. Sposito A, Caramelli B, Sartori AM Ramires JAF. The Lipoprotein Profile in HIV Infected Patients. Braz J Infect Dis 1997: 275-83.

53. Constans J, Pellegrin JL, Peuchant E et al. Plasma lipids in HIVinfected patients: a prospective study in 95 patients. Eur J Clin Invest 1994; 24: 416-20

54. Carr A, Samaras K, Chisholm DJ, Cooper D. Pathogenesis of HIV-1protease inhibitor-associated peripheral lipodistrophy, hyperlipidaemia, and insulin resistance. The Lancet 1998; 351: 1881-83.

55. Paton $\mathrm{P}$, Tabib A, Loire R, Tete R. Coronary artery lesions and human immunodeficiency virus infection. Res Virol 1993; 144 (3): 225-31.

56. Barbaro G, Barbarini G, Pellicelli A. HIV-Associated Coronary Arteritis in a Patient with Fatal Myocardial Infarction. N Engl J Med 2001; 344: 1799 
57. Rickerts V, Brodt H, Staszewski S, Stille W. Incidence of myocardial infarctions in HIV-infected patients between 1983 and 1998: the Frankfurt HIV-cohort study. Eur J Med Res 2000; 5 (8): 329-33.

58. Holmberg S, Moorman A, Williamson J et al. Protease inhibitors and cardiovascular outcomes in patients with HIV-1. The Lancet 2002; 360: $1747-8$.

59. Klein D, Hurley LB, Quesenberry Jr CP, Sidney S. Do protease inhibitors increase the risk for coronary heart disease in patients with HIV-1 infection? J AIDS 2002; 30: 471-7.

60. David M, Hornung R, Fichtenbaum CJ. Ischemic Cardiovascular Disease in Persons with Human Immunodeficiency Virus Infection. CID 2002; 34: 98-102.

61. Bozzette S, Ake C, Tam H, Chang S et al. Cardiovascular and Cerebrovascular Events in Patients Treated for Human Immunodeficiency Virus Infection. N Engl J Med 2003; 348: 702-10.

62. Currier J, Taylor A, Boyd F et al. Coronary Heart Disease in HIVInfected Individuals. J AIDS 2003; 33: 506-12.

63. The Data Collection on Adverse Events of Anti-HIV Drugs (DAD) Study Group. Combination Antiretroviral Therapy and the Risk of Myocardial Infarction. N Engl J Med 2003; 349: 1993-2003.

64. Tunstall-Pedoe H, Kuulasmaa K, Amouyel P, Arveiler D, Rajakangas AM, Pajak A. Myocardial infarction and coronary deaths in the World Health Organization MONICA Project: registration procedures, event rates, and case-fatality rates in 38 populations from 21 countries in four continents. Circulation 1994; 90: 583-612.

65. Varriale P, Saravi G, Hernandez E, Carbon F. Acute myocardial infarction in patients infected with human immunodeficiency virus. Am Heart J 2004; 147: 55-9.

66. Matetzky S, Domingo M, Kar S et al. Acute Myocardial Infarction in Human Immunodeficiency Virus-Infected Patients. Arch Intern Med 2003; 163: 457-60.

67. Hsue P, Giri K, Erickson S et al. Clinical Features of Acute Coronary Syndromes in Patients With Human Immunodeficiency Virus Infection. Circulation 2004; 109: 316-19.

68. Morrow DA, Antman EM, Charlesworth A et al. TIMI risk score for STelevation myocardial infarction: a convenient, bedside, clinical score for risk assessment at presentation. Circulation 2000; 102: 2031-7.

69. Antman EM, Cohen M, Bernink PJLM et al. The TIMI risk score for unstable angina/non-ST elevation MI: a method for prognostication and therapeutic decision making. JAMA 2000; 284: 835-42.

70. Bergersen BM, Sandvik L, Bruun JN, Tonstad S. Elevated Framingham risk score in HIV-positive patients on highly active antiretroviral therapy: results from a Norwegian study of 721 subjets. Eur J Clin Microbiol Infect Dis 2004; 23: 625-30.

71. Depairon M, Chessex S, Sudre P et al. Premature atherosclerosis in HIV-infected individuals-focus on protease inhibitor therapy. AIDS 2001; 15: 329-34.

72. Hsue P, Lo JC, Franklin A et al. Progression of atherosclerosis as assessed by carotid intima-media thickness in patients with HIV infection. Circulation 2004; 109: 1603-8.

73. III Diretrizes Brasileiras sobre Dislipidemia e Diretriz de Prevenção da Aterosclerose do Departamento de Aterosclerose da Sociedade Brasileira de Cardiologia Arq Bras Cardiol 2001; 77(supl. III).

74. Dube MP, Stein JH, Aberg JA et al. Guidelines for the evaluation and management of dyslipidemia in human immunodeficiency virus infected adults receiving antiretroviral therapy. Clin Infec Dis 2003; 37: 613-27.

75. Henry K, Melroe H, Huebsch J et al. Severe premature coronary artery disease with protease inhibitors. The Lancet 1998; 351: 1328

76. Périard D, Telenti A, Sudre P et al. Atherogenic dyslipidaemia in HIVinfected individuals treated with protease inhibitors. Circulation 1999; 100: 700-5.
77. Kannel WB, Giordano M. Long-term cardiovascular risk with protease inhibitors and management of the dyslipidemia. Am J Cardiol 2004; 94: 901-6

78. DATASUS. Estatísticas vitais. In: Ministério da Saúde; 2004

79. Selik RM, Lindegren ML. Changes in deaths reported with human immunodeficiency virus infection among United States children less than thirteen years old, 1987 through 1999. Pediatr Infect Dis J 2003; 22(7): 635-41.

80. Guyer B, MacDorman MF, Martin JA, Peters KD, Strobino DM. Annual summary of vital statistics-1997. Pediatrics 1998; 102 (6): 1333-49.

81. Kearney DL, Perez-Atayde AR, Easley KA et al. Postmortem cardiomegaly and echocardiographic measurements of left ventricular size and function in children infected with the human immunodeficiency virus. The Prospective P2C2 HIV Multicenter Study. Cardiovasc Pathol 2003; 12 (3):140-8.

82. Lipshultz SE, Easley KA, Orav EJ et al. Absence of cardiac toxicity of zidovudine in infants. Pediatric Pulmonary and Cardiac Complications of Vertically Transmitted HIV Infection Study Group. N Engl J Med 2000; 343 (11): 759-66.

83. Starc TJ, Lipshultz SE, Kaplan S et al. Cardiac complications in children with human immunodeficiency virus infection. Pediatric Pulmonary and Cardiac Complications of Vertically Transmitted HIV Infection (P2C2 HIV) Study Group, National Heart, Lung, and Blood Institute. Pediatrics 1999; 104(2): 14

84. Keesler MJ, Fisher SD, Lipshultz SE. Cardiac manifestations of HIV infection in infants and children. Ann N Y Acad Sci 2001; 946: 169-78.

85. Langston C, Cooper ER, Goldfarb J et al. Human immunodeficiency virus-related mortality in infants and children: data from the pediatric pulmonary and cardiovascular complications of vertically transmitted HIV (P(2)C(2)) Study. Pediatrics 2001; 107 (2): 328-38

86. Fisher SD, Lipshultz SE. Epidemiology of cardiovascular involvement in HIV disease and AIDS. Ann N Y Acad Sci 2001; 946: 13-22.

87. Velasquez EM, Glancy DL. Cardiovascular disease in patients infected with the human immunodeficiency virus. J La State Med Soc 2003; 155 (6): 314-24.

88. Herdy GV, Ramos R, Bazin AR et al. Correlação histopatológica em 50 casos de Síndrome de Imunodeficiência Adquirida. Um estudo retrospectivo. Arq Bras Cardiol 1994; 62 (2): 95-8.

89. Shearer WT, Lipshultz SE, Easley KA et al. Alterations in cardiac and pulmonary function in pediatric rapid human immunodeficiency virus type 1 disease progressors. Pediatric Pulmonary and Cardiovascular Complications of Vertically Transmitted Human Immunodeficiency Virus Study Group. Pediatrics 2000; 105 (1): 9.

90. Nogueira G, Macedo AJ, Paixao A et al. Morbidade cardiovascular em crianças com infecção pelo vírus da Imunodeficiência Humana. Acta Med Port 1998; 11 (12): 1051-7.

91. Bannerman C, Chitsike I. Cor pulmonale in children with human immunodeficiency virus infection. Ann Trop Paediatr 1995; 15 (2): 129-34.

92. Mehta NJ, Khan IA, Mehta RN, Sepkowitz DA. HIV-Related pulmonary hypertension: analytic review of 131 cases. Chest 2000; 118 (4): 1133-41.

93. Lipshultz SE, Orav EJ, Sanders SP, Colan SD. Immunoglobulins and left ventricular structure and function in pediatric HIV infection. Circulation 1995; 92 (8): 2220-5

94. Lai WW, Colan SD, Easley KA et al. Dilation of the aortic root in children infected with human immunodeficiency virus type 1: The Prospective P2C2 HIV Multicenter Study. Am Heart J 2001; 141 (4): 661-70.

95. Bowles NE, Kearney DL, Ni J et al. The detection of viral genomes by polymerase chain reaction in the myocardium of pediatric patients with advanced HIV disease. J Am Coll Cardiol 1999; 34 (3): 857-65. 
96. Domanski MJ, Sloas MM, Follmann DA et al. Effect of zidovudine and didanosine treatment on heart function in children infected with human immunodeficiency virus. J Pediatr 1995; 127 (1): 137-46.

97. Herdy GV, Pinto CA, Lopes VG et al. Study of the cardiac alterations in HIV-infected children consequent to the antiretroviral therapy. Prospective study of 47 cases. Arq Bras Cardiol 2003; 80 (3): 311-20.

98. Bezold LI, Bricker JT. Acquired heart disease in children. Curr Opin Cardiol 1994; 9 (1): 121-9.

99. Cossarizza A, Troiano L, Mussini C. Mitochondria and HIV infection: the first decade. J Biol Regul Homeost Agents 2002; 16 (1): 18-24.

100. de Larranaga GF, Petroni A, Deluchi G, Alonso BS, Benetucci JA. Viral load and disease progression as responsible for endothelial activation and/or injury in human immunodeficiency virus-1-infected patients. Blood Coagul Fibrinolysis 2003; 14 (1): 15-8.
101. Matzen K, Dirkx AE, Oude Egbrink MG et al. HIV-1 Tat increases the adhesion of monocytes and T-cells to the endothelium in vitro and in vivo: implications for AIDS-associated vasculopathy. Virus Res 2004; 104 (2): 145-55

102. Bonnet D, Aggoun Y, Szezepanski I, Bellal N, Blanche S. Arterial stiffness and endothelial dysfunction in HIV-infected children. Aids 2004; 18 (7): 1037-41.

103.Cheseaux JJ, Jotterand V, Aebi C et al. Hyperlipidemia in HIV-infected children treated with protease inhibitors: relevance for cardiovascular diseases. J Acquir Immune Defic Syndr 2002; 30 (3): 288-93.

104. Wolf K, Tsakiris DA, Weber R, Erb P, Battegay M. Antiretroviral therapy reduces markers of endothelial and coagulation activation in patients infected with human immunodeficiency virus type 1 . J Infect Dis 2002 ; 185 (4): 456-62. 